\title{
O ENSINO DE FILOSOFIA E A CRIAÇÃO DE CONCEITOS
}

\author{
Simone Gallina*
}

\begin{abstract}
RESUMO: Ao pensar as linhas e os traçados do ensino em filosofia, tem-se que levar em conta que esta atividade pedagógica deve se constituir numa atividade filosófica e, ainda dependendo da concepção de atividade filosófica, que devemos modificar significativamente a própria concepção do que consiste o ensino e a aprendizagem em filosofia. Neste sentido, torna-se importante esclarecer em que consiste a atividade filosófica para se mapear os territórios do ensino em filosofia. Tarefa esta que nos propomos a partir da contribuição do filósofo francês Gilles Deleuze, o qual, em seus inúmeros escritos, afirma que a atividade do filósofo implica uma dimensão de criação: criação de conceitos.
\end{abstract}

Palavras-chave: Filosofia. História. Ensino. Leitura. Conceito.

\section{THE TEACHING OF PHILOSOPHY AND THE CREATION OF CONCEPTS}

ABSTRACT: When thinking the lines and tracings in philosophy teaching, it should take into consideration that this pedagogical activity should be constituted in a philosophical activity and, still depending on the conception of the philosophical activity, we will change significantly the proper conception of what consists the teaching and the learning of philosophy. In this sense, it is important to clarify what consists the philosophical activity to outline the territories of teaching of philosophy. We propose this task considering the contribution of the French philosopher Gilles Deleuze who, in his innumerable writings, affirms that the activity of the philosopher implies a dimension of creation: creation of concepts.

Key words: Philosophy. History. Teaching. Reading. Concept.

Mestra em educação pela Universidade Federal de Santa Maria (UFSM) e doutoranda na Faculdade de Educação da Universidade Estadual de Campinas (UNICAMP). E-mail: sigalli@terra.com.br 


\section{Ensino de filosofia e a história da filosofia}

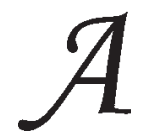

ausência de clareza acerca do ensino de filosofia resulta da atribuição de uma certa primazia do que convencionamos chamar de temas próprios da atividade filosófica. Ao que parece, não são somente os conteúdos empregados no ensino de filosofia que a constituem como atividade filosófica, mas, antes, o que a torna uma tal atividade propriamente filosófica. Convém observar que ao dizermos isso não estamos querendo negar a pertinência da didática, mas tão-somente que ela depende, em última instância, da delimitação daquilo que consiste propriamente no ensino de filosofia como atividade filosófica.

$\mathrm{Na}$ década de 1980 ocorreram intensos debates sobre o ensino de filosofia, os quais são importantes na medida em que nos mostram não somente o que pensam os filósofos brasileiros sobre a filosofia e o seu ensino, mas também a sua influência às futuras geraçōes de professores de filosofia. Um bom exemplo pode ser encontrado no livro intitulado $O$ ensino da filosofia no $2^{\circ}$ grau, organizado em 1986 por Henrique Nielsen Neto. Nele podemos observar que, para alguns filósofos, o ensino de filosofia deve ser orientado tanto pelo estudo da história da filosofia quanto pela discussão dos temas filosóficos concernentes ao cotidiano. Propōe-se também que a disciplina seja pensada mediante atividades de exposição temática e discussão sobre tais temas, perfazendo o percurso que vai desde a filosofia antiga até as questôes da filosofia contemporânea. Nesse mesmo livro também encontramos argumentos em defesa de temas específicos a serem ensinados. Certamente essa abordagem do ensino de filosofia, como estritamente vinculado à escolha dos conteúdos, está mais preocupada com as concepçōes individuais dos professores da disciplina no ensino médio, estabelecendo assim uma espécie de programa mínimo para o ensino de filosofia. Objetivo que também fica manifesto nos manuais didáticos, nos quais freqüentemente lemos que o ensino de filosofia requer uma visita ao mundo da filosofia e aos conteúdos que nele se encontram.

Por um lado, a amplitude e abrangência do que pode servir de tema para o ensino de filosofia, conforme se pode perceber nas propostas acima mencionadas, mostram que não se pode determinar a priori o que irá servir como conteúdo para o ensino de filosofia. Por outro, a determinação dos temas não assegura que a atividade desenvolvida pelo professor de filosofia seja uma atividade propriamente filosófica. 
Mesmo que as propostas temáticas representem a tradição filosófica e mesmo que a escolha dos temas seja oriunda de uma decisão pautada por critérios filosóficos, ainda assim, apoiar o ensino de filosofia na história da filosofia, como fonte de problemas e de soluçóes, pode resultar numa atividade que perde de vista uma condição inerente à atividade do filósofo: a criação conceitual, o nascimento do novo:

A maior parte do tempo, quando me colocam uma questão, mesmo que ela me interesse, percebo que não tenho estritamente nada a dizer. As questōes são fabricadas, como outra coisa qualquer. Se não deixam que você fabrique suas questôes, com elementos vindos de toda parte, de qualquer lugar, se as colocam a você, não tem muito o que dizer. A arte de construir um problema é muito importante: inventa-se um problema, uma posição de problema, antes de se encontrar a solução. (Deleuze \& Parnet, 1998, p. 9)

Contudo, há um aspecto importante no debate da década de 1980: o resgate do cotidiano para o ensino de filosofia. Porém, esse resgate acontece somente à medida que é tomado como um acontecimento.

O que a história capta do acontecimento é a sua efetuação em estados de coisas, mas o acontecimento em seu devir escapa à história. A história não é a experimentação, ela é apenas o conjunto das condições quase negativas que possibilitam a experimentação de algo que escapa à história. Sem a história, a experimentação permaneceria indeterminada, incondicionada, mas a experimentação não é histórica. (...) O devir não é história; a história designa somente o conjunto das condiçōes, por mais recentes que sejam, das quais se desvia a fim de "devir", isto é, para criar algo novo. (Deleuze, 1992, p. 210-211)

O ensino de filosofia não pode prescindir do acontecimento, de onde emergem os devires que orientam a elaboração de problemas. Os problemas filosóficos não se encontram nos textos dos filósofos e sequer podem ser comunicados pelos professores de filosofia; eles estão submetidos aos devires, às orientações e às direções que não pertencem à história da filosofia, mas do acontecimento. Mesmo que os problemas estejam orientados para o passado ou para o futuro, eles estão submetidos às multiplicidades, aos devires que emergem como forças que operam em silêncio. Os problemas emergem dos acontecimentos e das experimentações. 


\section{Os agenciamentos da leitura}

Uma outra conseqüência da ausência de clareza acerca do ensino de filosofia resulta de algumas incompreensões geradas a partir de uma suposta necessidade de métodos, de procedimentos próprios à atividade filosófica e, conseqüentemente, da sua necessidade para o ensino de filosofia. Sem dúvida as técnicas e os procedimentos são importantes para a filosofia, mas isso não significa que o método seja o meio pelo qual se aprende filosofia.

O trabalho de Sonia Maria Ribeiro de Souza trouxe significativas contribuições para o ensino de filosofia, a sua abordagem histórico-didática é importante na medida em que permite um diálogo sobre a relação entre método e ensino. Segundo a autora, a utilização do método visa à obtenção de um fim determinado, isto é, ele tem "a finalidade de produzir nos alunos mudanças de atitudes expressas nos objetivos educacionais" (Souza, 1992, p. 100). O recurso a esta concepção genérica de método se dá em função da dificuldade da apropriação de um método filosófico para o ensino de filosofia. O método seria uma espécie de "característica essencial da filosofia", contudo não há um único método, antes sim métodos, os quais seriam "peculiares a cada filósofo, são na verdade, únicos e irrepetíveis e, neste sentido, há tantos métodos filosóficos quanto os filósofos que existiram e que existem na face da Terra" (idem, ibid.).

Além dessa gama de métodos, o que causa um certo embaraço quanto à escolha daquele que seria o mais apropriado, o problema com eles é que são "irrepetíveis", isto é, a sua singularidade implica a impossibilidade de serem separados de seus próprios autores. A conclusão sobre um método genuinamente filosófico é que os métodos da filosofia "não se configuram como os mais adequados para o ensino da filosofia" (idem, ibid.). Mesmo assim, existem alguns métodos comuns a outras áreas do saber que podem ser utilizados no ensino de filosofia. Entre eles figura o "método expositivo", o "método interrogativo", o "método de exposição dialogada", o "método de leitura e análise de textos", o "método de análise lingüística" e o "estudo dirigido" (idem, ibid.). A utilização desses métodos depende do professor, contudo cada um deles obedece a uma lógica própria, o que não impede que o professor estabeleça inovações no sentido do aprimoramento deles.

Os dois métodos destacados como mais pertinentes são o método de exposição dialogada e o método de leitura e análise de textos. O pri- 
meiro é, "do ponto de vista de muitos educadores, o mais adequado para o processo de ensino-aprendizagem da referida disciplina" (idem, ibid., p. 105), ao passo que o segundo, por sua vez, é importante porque as suas metas "condensam a finalidade central da disciplina no $2^{\circ}$ grau: ensinar o aluno a filosofar" (idem, ibid., p. 108). Como se pode observar, dos dois o preferido pela autora é o concernente à leitura, visto que ele cumpriria uma finalidade própria ao ensino de filosofia, ou seja, ensinar a filosofar.

As "metas pedagógicas", apresentadas como finalidades do método de leitura e análise de textos, próprias ao ensino de filosofia de acordo com Souza são as seguintes: "compreensão global do pensamento de um autor, bem como de uma escola ou corrente filosófica de um determinado período do qual o filósofo é um representante; o acesso à filosofia por meio desse pensamento e, por último, a aquisição de uma técnica intelectual e de análise filosófica" (ibid., p. 108). Ocorre que, a despeito da ênfase dada pela autora, parece pouco crível que uma tal compreensão da leitura de fato ensine a filosofar. Afora as expressões que denotam uma relação com a filosofia, a caracterização dessas metas pode servir para a leitura em qualquer outra disciplina.

Ao finalizar a explicitação do referido método, a autora afirma que este "implica um esforço de compreensão da linguagem dos filósofos, isto é, uma abordagem dos termos, dos enunciados, dos encadeamentos discursivos e das várias expressóes usadas pelos autores lidos, por meio das quais o filósofo procura comunicar o produto de sua reflexão filosófica” (idem, ibid., p. 112). Será que o esforço para compreender termos, enunciados, encadeamentos, expressões nos conduzem à criação conceitual? $\mathrm{Ou}$ talvez nos sejam extremamente úteis para assimilar e reter um "produto" pronto e acabado?

Pode-se concordar com a autora que os textos dos filósofos exercem influência e são determinantes para as atividades filosóficas. Também parece acertado dizer que a relação com tais textos é uma relação de leitura. Contudo, a afirmação de que os textos dos filósofos comunicam o produto da sua reflexão, o qual poderá ser compreendido com a aplicação do método de análise, parece não levar em conta a diferença entre uma leitura filosófica e uma leitura histórica desses textos. Mas o que seria propriamente uma leitura apenas histórica dos textos dos filósofos e por que ela pode pôr em risco o ensino de filosofia?

Uma leitura histórica nada mais é que uma atualização de lembranças. Pascal Chabot diz que uma lembrança atualizada perde o virtual "por- 
que ela é uma diferença selecionada" (1998, p. 43), ou seja, ao serem atualizadas, as intensidades acabam "coaguladas em estados de coisas definidos" (ibid., p. 43), transformam-se em formas estáveis. Ao contrário, "uma arte imanente de interpretação" (ibid., p. 40) mantém o movimento que caracteriza as densidades como multiplicidades virtuais, como singularidades. A leitura filosófica, na qualidade dessa arte imanente, dissolve o que é coagulado na representação, conservando as forças e as intensidades passadas que dão consistência e coerência à diversidade de atualizaçóes produzidas pelo virtual.

Apoiar a leitura no método de análise inviabiliza o caráter filosófico da própria leitura. Se o problema for reduzido a uma instância proposicional, a verdade desse problema consistiria somente em que ele possui uma solução. Ao contrário disso, poderíamos pensar que, se há um sentido na interpretação, este está no problema e não no emaranhado de proposições que tecem e tramam o texto. Um tal sentido estaria longe de qualquer posição que prime pela resolução e também daquelas que vêem no método um bom guia para a busca de sentido para o texto.

Pensar um problema, mesmo a partir de um texto, é antes de tudo engendrar descontinuidades, gerar soluções, evitando com isso a velha ilusão de que um problema sempre visa a uma determinada solução. Também é preciso atentar para a existência de uma diferença de natureza entre proposições e problemas. Problemas não podem ser decalcados das proposições, sob pena de se perder a própria aprendizagem da multiplicidade de relaçóes.

A boa maneira para se ler hoje, porém, é a de conseguir tratar um livro como se escuta um disco, como se vê um filme ou um programa de televisão, como se recebe uma canção: qualquer tratamento do livro que reclamasse para ele um respeito especial, uma atenção de outro tipo, vem de outra época e condena definitivamente o livro. Não há questão alguma de dificuldade nem de compreensão: os conceitos são exatamente como sons, cores ou imagens, são intensidades que lhes convêm ou não, que passam ou não passam. (...) Gostaria de dizer que é um estilo (...). E um agenciamento, um agenciamento de enunciação. Conseguir gaguejar em sua própria língua, é isso um estilo. É difícil porque é preciso que haja necessidade de tal gagueira. Ser gago não em sua fala, e sim ser gago da própria linguagem. Ser como um estrangeiro em sua própria língua. Traçar uma linha de fuga. (Deleuze \& Parnet, 1998, p. 11-12)

Talvez seja justamente essa maneira de ler os livros, como uma espécie de língua estrangeira, que tenha atraído a atenção de Deleuze para 
a obra de Proust. A maneira como Proust se refere à leitura de um livro, a partir do qual os contra-sensos criam uma língua no interior da língua, obrigam o leitor a usar o livro e a saber lidar com as linhas de fuga que lhe são inerentes. Porém, esse agenciamento da leitura nos coloca um problema com relação ao ensino da filosofia na medida em que o pensamos como uma atividade de leitura regrada por um método. Da proposta anterior sobre a leitura, segundo o que foi afirmado nas metas e nos resultados, pode-se inferir que nos textos dos filósofos se encontram verdades, cujo acesso depende do esforço de compreensão e da utilização correta do método. Mesmo que a autora não tenha afirmado e sequer feito menção a esta questão, a possibilidade de uma tal inferência nos remeteria a um outro problema implicado na utilização do método de leitura, ou seja, que a atividade filosófica consiste em descobrir verdades escondidas nos textos. Sobre esta questão a referência de Deleuze a Proust é muito relevante:

A crítica de Proust toca no essencial: as verdades permanecem arbitrárias e abstratas enquanto se fundam na boa vontade de pensar. Apenas o convencional é explícito. Razão pela qual a filosofia, como a amizade, ignora as zonas obscuras em que são elaboradas as forças efetivas que agem sobre o pensamento, as determinações que nos forçam a pensar. Não basta uma boa vontade nem um método bem elaborado para ensinar a pensar, como não basta um amigo para nos aproximarmos do verdadeiro. Os espíritos só se comunicam no convencional; o espírito só engendra o possível. Às verdades da filosofia faltam a necessidade e a marca da necessidade. De fato, a verdade não se dá, se trai; não se comunica, se interpreta; não é voluntária, é involuntária. (Deleuze, 2003, p. 89)

Por um lado, dizer que existem verdades nos textos filosóficos parece ser um bom pressuposto para requerer um método que permita encontrá-las, por outro, isso se torna tão problemático quanto afirmar que existem textos verdadeiros e, conseqüentemente, outros que seriam falsos. Neste sentido, não há por que reivindicar a pertinência de um método para se alcançar a verdade. Isso somente tem sentido para aqueles que, a partir de uma imagem do pensamento como cogitatio natura universalis, pensam que a filosofia tende naturalmente para o verdadeiro. A filosofia não requer uma boa vontade do pensador e uma natureza reta do pensamento, sequer decisão e método, porque não é a verdade e sim o interesse que serve de inspiração para a filosofia e para o fazer filosófico. 


\section{Os territórios da atividade filosófica}

Deleuze critica a concepção da história da filosofia como imagem do transcendente, como se a história da filosofia pudesse ser comparada com um retrato. Para ele, esta concepção opera por decalques, por estagnação do fluxo das intensidades, concebendo a filosofia como uma busca de verdades, apoiando-se numa imagem do pensamento cujos pressupostos são morais. A idéia de uma cogitatio natura universalis confere ao pensamento uma natureza boa e, conseqüentemente, o pensador é dotado de uma boa vontade que lhe permite alcançar o verdadeiro (Cf. Deleuze, 1988 , p. $215-235)$. Deleuze atribui esta imagem do pensamento ao modelo da recognição. Um modelo que orienta a análise do que significa o pensar, e que tem na teoria da representação seu apogeu, mais precisamente numa teoria para a qual a identidade do objeto está fundada na unidade do sujeito pensante e na relação de concordância das suas faculdades, dos seus modos.

O problema com esta imagem do pensamento é que ela perde de vista a diferença e a repetição em si mesmas, fazendo com que o objeto, o que é signo para a alma, deixe de ser ou de suscitar um problema. O objeto acaba sendo o Mesmo, tal como um retrato, e a filosofia, a arte de retratar. Contudo, na atividade filosófica "não se trata de 'fazer parecido', isto é, de repetir o que o filósofo disse, mas de produzir a semelhança, desnudando ao mesmo tempo o plano de imanência que ele instaurou e os novos conceitos que criou" (Deleuze \& Guattari, 1992, p. 74). A verdade dos escritos e mesmo do próprio pensamento está pressuposta na possibilidade da criação de conceitos filosóficos, ela é somente o que o pensamento cria, pois o pensamento é criação. Ora, se "a filosofia supõe enunciados diretos e significações explícitas saídos de um espírito que quer a verdade", então "erramos quando acreditamos na verdade: só há interpretaçôes" (Deleuze, 2003, p. 86). Com isso, Deleuze afasta-se daqueles que, como os filósofos modernos, pressupõem uma imagem do pensamento.

Talvez esta seja a razão para que Deleuze insista na desconfiança filosófica apregoada por Nietzsche, o qual aconselhava os filósofos a desconfiarem dos conceitos que por eles mesmos não tivessem sido criados. Neste sentido se pode compreender o quanto é imprescindível à atividade do filósofo uma relação com a tradição filosófica de desconfiança, pois é a partir do território do dado que será possível atualizar conceitos. Ou seja, fabricá-los e não somente "fazê-los reluzir" (Cf. Deleuze \& Guattari, 
1992, p. 14). Mas isso nos põe em contato com uma das principais características atribuídas à atividade do filósofo, qual seja, a condição de que no conceito criado esteja implícita a singularidade daquele que o criou. Pois ao dizer que "pensar e ser são uma só e mesma coisa" (idem, ibid., p. 54), afirma-se que o conceito é sempre acompanhado de um estilo, de uma assinatura própria daquele que pensa e cria um determinado conceito.

A atividade de criação do filósofo é um agenciamento que garante um registro único, singular, perante a tradição filosófica. A capacidade para constituir ou inventar problemas, cuja solução depende da multiplicidade de relações, das singularidades e, sobretudo, depende da determinação das condições do próprio problema, é a capacidade que torna possível o surgimento do filósofo. Ao problematizar, o filósofo institui um plano de imanência, no qual a atividade filosófica criadora deixará de ser o tipo de atividade que historicamente a ela tem sido atribuído, ou seja, que a atividade própria do filósofo é a contemplação, reflexão, discussão ou comunicação. Tais denominações podem ser invocadas pela ciência ou pela arte, mas jamais pela filosofia, mesmo que esta mantenha uma condição de "vizinhança" com aquelas.

Poderíamos perguntar: Por que a filosofia é a única que produz conceitos? Por não poder criar o Uno, "a filosofia faz surgir acontecimentos com seus conceitos", ao passo que "a arte ergue monumentos com suas sensações, a ciência constrói estados de coisas com suas funções” (idem, ibid., p. 255). Os conceitos são cifras sem preexistência e é isso que faz deles acontecimentos singulares. Acontecimentos cifrados, garantia de uma temporalidade ao conceito que não se refere nem ao passado, nem ao presente e muito menos ao futuro. Uma temporalidade que diz da ordem do "adormecido", em que o imprescindível para o conceito é poder fazer parte de uma nova cena: "O acontecimento é talvez a figura contemporânea do álteron, do que não pode ser integrado, nem identificado, nem compreendido, nem previsto. Outras palavras que podem nomear também, ainda que de outro modo, o acontecimento são, por exemplo, interrupção, novidade, catástrofe, surpresa, começo, nascimento, milagre, revolução, criação, liberdade" (Larrosa, 2001, p. 282). Contudo, será que podemos com esta noção de filosofia, como atividade criadora de conceitos, afirmar que a tradição filosófica se constitui numa fonte de acontecimentos importantes para o ensino da filosofia? 
A condição atribuída ao conceito de ser um começo, um nascimento, uma criação, uma novidade, traz consigo a necessidade de concebê-lo como pertencendo ao domínio do porvir. Esta condição implica de antemão que qualquer contribuição da tradição filosófica está intimamente relacionada com uma atividade cuja principal característica seja a intensa criação. Uma atividade que permite surgir, a partir do mesmo, a heterogeneidade, a diferença.

É possível darmos uma definição sobre a filosofia? Ou, podemos chegar a um consenso sobre o que é a filosofia? Sim, mas desde que a verdade implicada nessa definição não seja mais entendida no sentido da adequação ou correspondência, tal como ocorre com a concepção do conhecimento em termos de representação. Mas, ao mudarmos o referencial pelo qual se orienta a verdade, deixamos de pensar a definição como indicador de essências ou de propriedades de coisas, como se dá no conhecimento, passamos a pensá-la como comportando uma dimensão produtiva. Neste sentido, podemos dizer que "a filosofia, mais rigorosamente, é a disciplina que consiste em criar conceitos” (Deleuze \& Guattari, 1992, p. 13). Com isso, a própria definição do conceito sofre uma mudança, pois, se "a filosofia não é uma simples arte de formar, de inventar ou de fabricar conceitos", implica que os "conceitos não são necessariamente formas, achados ou produtos" (idem, ibid., p. 13). O conceito é algo criado e, como tal, implica uma habilidade que só ao filósofo pertence, uma atividade à qual consiste propriamente o nome de filosofia.

Nunca se sabe de antemão como alguém vai aprender - que amores tornam alguém bom em Latim, por meio de que encontros se é filósofo, em que dicionários se aprende a pensar (...). Não há método para encontrar tesouros nem para aprender, mas um violento adestramento, uma cultura ou uma paideia que percorre inteiramente todo o indivíduo (um albino em que nasce o ato de sentir na sensibilidade, um afásico em que nasce a fala na linguagem, um acéfalo em que nasce pensar no pensamento). (Deleuze, 1988, p. 270)

A atividade filosófica ocupa-se com as condições que permitem a formulação de problemas, e nisso consiste a aprendizagem em filosofia. Mesmo que os problemas estejam na base da produção conceitual, esta não é uma decorrência direta do método, como se o método permitisse uma passagem direta do não-saber ao saber. Ou seja, mesmo que a produção conceitual seja um momento da aprendizagem, isso ocorre somente 
porque ela resulta de uma intensa atividade na qual o método não tem nenhuma significativa importância. Pois a aprendizagem dá-se na constituição dos problemas e estes se passam sempre pelo e no inconsciente.

Que toda filosofia dependa de uma intuição, que seus conceitos não cessam de desenvolver até o limite das diferenças de intensidade, esta grandiosa perspectiva leibniziana ou bergsoniana está fundada se consideramos a intuição como o desenvolvimento dos movimentos infinitos do pensamento, que percorrem sem cessar um plano de imanência. Não se concluirá daí que os conceitos se deduzam do plano: para tanto é necessária uma construção especial, distinta daquela do plano, e é por isso que os conceitos devem ser criados, do mesmo modo que o plano deve ser erigido. (...) Se a filosofia começa com a criação de conceitos, o plano de imanência deve ser considerado como pré-filosófico. Ele está pressuposto, não da maneira pela qual um conceito pode remeter a outros, mas pela qual os conceitos remetem eles mesmos a uma compreensão não-conceitual. (Deleuze \& Guatarri, 1992, p. 56-57)

Ao definirmos a filosofia como uma atividade, estamos excluindo dessa definição outras noçôes que habitualmente são identificadas como próprias da filosofia. A filosofia não pode mais ser pensada como uma reflexão, uma comunicação ou ainda uma contemplação, formas pelas quais ela sempre foi considerada, mas como uma operação de criação de conceitos. O conceito não pode ser confundido com uma proposição, porque ele não tem um valor de verdade, não se refere a estados de coisas, como é o caso das proposições da ciência. Como criação singular, o conceito reporta-se a um acontecimento, ele próprio é um acontecimento. Ora, considerar o conceito um acontecimento implica também considerar que o filosofar deve se ater às circunstâncias implicadas na criação conceitual, aos casos, onde, quando, como etc. Pois são estes elementos circunstanciais que caracterizam o conceito como singularidade, como algo datado, mas também como algo que muda, conforme são operadas as relações que o definem.

Se o conceito está implicado num conjunto de relações em constante devir, então a própria história da filosofia também precisa ser pensada como um devir filosófico. Como devir, a história da filosofia não pode ser considerada mediante uma noção de temporalidade que se restringe à relação presente-passado, antes sim à relação atual-virtual. Desta concepção da história da filosofia como virtual pode surgir uma nova concepção de leitura: a leitura da história da filosofia passa a ser uma atu- 
alização de intensidades virtuais. Talvez desse modo estaremos evitando transformar a filosofia e o seu ensino numa atividade de doxografia, contentando-se apenas com proposições ou simples opiniōes:

É sempre a mesma melancolia que se eleva das Questôes disputadas e dos Quodlibets da Idade Média, em que se aprende o que cada doutor pensou, sem saber por que ele o pensou (o Acontecimento), e que se encontra em muitas histórias da filosofia onde se passam em revista as soluçôes, sem jamais saber qual é o problema (a substância em Aristóteles, em Descartes, em Leibniz...), já que o problema é somente decalcado das proposições que lhe servem de resposta. (Deleuze \& Guattari, 1992, p. 105)

Da mesma forma que, em filosofia, a aprendizagem não tem sua origem na atividade orientada pela objetividade metodológica, também não pode ser vista como uma atividade cujo fim remete a uma simples aquisição de saberes. Pois, se tem sentido falar de aprendizagem em filosofia, esta deve ser reportada à constituição de problemas na qual estão envolvidos agenciamentos de desejos. Pois aquele que se envolve com a filosofia é como um nômade, cuja criação conceitual se parece com a atividade daquele cuja experiência se dá num território onde os relevos constantemente se modificam.

Recebido em maio de 2004 e aprovado em junho de 2004

\section{Referências bibliográficas}

BOAVIDA, J. Filosofia - do ser e do ensinar: proposta para uma nova abordagem. Coimbra: Imprensa Nacional; Casa da Moeda, 1991.

CHABOT, P. Au seuil du virtuel. In: Verstraeten, P.; Stengers, I. (Coord.). Gilles Deleuze. Paris: Librairie Philosophique J. Vrin, 1998. p. 31-44.

DELEUZE, G.; GUATTARI, F. O que é a filosofia? Tradução de Bento Prado Jr. e Alberto Alonso Muñoz. Rio de Janeiro: 34, 1992.

DELEUZE, G.; PARNET, C. Diálogos. Trad. de Eloisa Araújo Ribeiro. São Paulo: Escuta, 1998. 
DELEUZE, G. Diferença e repetição. Tradução de Luiz Orlandi e Roberto Machado. Rio de Janeiro: Graal, 1988.

DELEUZE, G. Conversaçôes. Trad. de Peter Pál Pelbart. Rio de Janeiro: 34, 1992.

DELEUZE, G. Proust e os signos. 2. ed. Trad. de Antonio Carlos Piquet e Roberto Machado. Rio de Janeiro: Forense Universitária, 2003.

LARROSA, J. Dar a palavra. Notas para uma dialógica da transmissão. In: Larrosa, J.; Skliar, C. (Org.). Habitantes de Babel: políticas da diferença. Belo Horizonte: Autêntica, 2001. p. 281-295.

NIELSEN NETO, H. (Org.). O ensino da filosofia no $2^{\circ}$ grau. São Paulo: Sofia, 1986.

SOUZA, S.M.R. Por que Filosofia? Uma abordagem histórico-didática do ensino de filosofia no $2^{\circ}$ grau. 1992. 116p. Tese (doutorado) - Faculdade de Educação. Universidade Estadual de São Paulo, São Paulo. 